\title{
Estimated prevalence and predictors of undernutrition among children aged 5-17 months in Yerevan, Armenia
}

\author{
Lilit Hovhannisyan, Anahit Demirchyan* and Varduhi Petrosyan \\ College of Health Sciences, American University of Armenia, 40 Marshal Baghramian Avenue, \\ Yerevan 0019, Armenia
}

Submitted 16 November 2012: Final revision received 19 March 2013: Accepted 20 March 2013: First published online 14 May 2013

\begin{abstract}
Objective: Child undernutrition is a serious public health problem in many lowand middle-income countries. Data on child undernutrition prevalence and its risk factors in Armenia are limited. The present study aimed to estimate the prevalence and explore the predictors of undernutrition among children aged 5-17 months in Yerevan.

Design: The study was cross-sectional and employed a review of the ambulatory charts of children selected through a multistage cluster sampling. This phase was followed by a case-control study. The cases were undernourished children identified during the record review and randomly matched with normally growing controls of the same age and gender from the same pool of records. Mothers of cases and controls participated in a telephone interview. The study used conditional logistic regression analysis.

Setting: Yerevan, Armenia.

Subjects: Children aged 5-17 months residing in Yerevan, Armenia.

Results: Review of 570 ambulatory charts suggested the prevalence of stunting, underweight and wasting among 5-17-month-old children in Yerevan to be $17.9 \%$, $7 \cdot 3 \%$ and $3 \cdot 1 \%$, respectively. The case-control study of eighty-nine matched pairs identified four significant predictors of child undernutrition: family's socio-economic status score $(P=0 \cdot 030)$, child's length at birth $(P=0 \cdot 027)$, duration of predominant breast-feeding $(P=0 \cdot 046)$ and food diversity score $(P=0 \cdot 039)$.

Conclusions: The factors determining growth patterns of children in Yerevan are mostly behavioral and environmental, hence modifiable. Reducing poverty and inequalities in food availability, promoting breast-feeding and adequate complementary feeding, and ensuring optimal care before, during and after pregnancy are likely to help reduce child undernutrition in Yerevan, Armenia and societies with similar public health concerns.
\end{abstract}

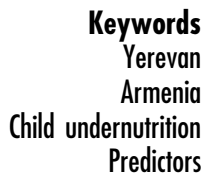

It is widely recognized that child undernutrition is a serious problem leading to numerous health consequences such as poor cognitive development, restricted growth, reduced immunity, higher morbidity and death ${ }^{(1-5)}$. Although the prevalence of undernutrition is declining globally, it remains a major public health problem in many countries ${ }^{(6,7)}$. According to $\mathrm{WHO}$, the prevalence of underweight and stunting among children under 5 years of age is estimated to be $16 \%$ and $27 \%$ worldwide, respectively ${ }^{(8)}$. Childhood and maternal underweight is the leading cause of the global burden of disease, accounting for 138 million disabilityadjusted life years ${ }^{(9)}$. Undernutrition and intra-uterine growth restriction cause $2 \cdot 2$ million deaths annually among children under 5 years of age - a substantial proportion of all deaths occurring in infancy and childhood ${ }^{(10,11)}$.

Many studies suggest that poor socio-economic status (SES), low level of mother's education, larger family size with many siblings under 5 years of age and shorter inter-birth intervals are risk factors for child undernutrition $^{(12-20)}$, while higher levels of per capita public spending on health care are proved to contribute to better health outcomes among the poor and dramatically reduce mortality and undernutrition of children from poor families $^{(21)}$. Health-related risk factors for child undernutrition include maternal common mental disorders, poor nutritional status of mothers, child's small size at birth and recurrent infections ${ }^{(12-14,16,18,22,23)}$. The protective effect of breast-feeding against child malnutrition is well established $^{(12,13,24)}$. In addition to supplying superior infant nutrition, breast-feeding provides strong protection against infections ${ }^{(25-27)}$.

Cross-cultural comparisons of infant growth rates show that growth patterns of breast-fed infants who receive timely and adequate complementary feeding are similar 
across different populations. Altered growth among these infants is largely attributable to prenatal factors and maternal stature ${ }^{(28)}$. Therefore, WHO developed and recommended use of the Child Growth Standards ${ }^{(29)}$ based on the growth rate of infants receiving optimal feeding, which is defined as exclusive breast-feeding during the first 6 months and adequate complementary feeding starting at 6 months of age with continuation of breast-feeding into the second year of life. These standards replaced the older standards recommended by WHO that used the 1977 International Reference Population defined by the US National Center for Health Statistics $(\mathrm{NCHS})^{(30)}$.

Data on prevalence and determinants of child undernutrition in Armenia are limited. Armenia lacks a surveillance system for child growth. Primary health-care facilities are responsible for child growth monitoring. However, these measurements are neither summarized at a regional or national level, nor are they analysed or used for policy or other decision making. Studies with limited or national coverage have been the only sources of data on children's nutritional status. According to the earliest available estimates from $1993^{(31)}$, the prevalence of stunting among children aged $0 \cdot 5-5$ years in Armenia was $6 \cdot 2 \%$, underweight prevalence was $4.7 \%$ and wasting prevalence was $1.0 \%$ (all rates were defined as percentages of children who were more than two standard deviations below the median of the NCHS/WHO reference population $\left.{ }^{(32)}\right)$. In Yerevan, these rates were $8.0 \%, 2 \cdot 3 \%$ and $1.2 \%$ in 1993 and $5 \cdot 9 \%, 1 \cdot 6 \%$ and $0.6 \%$ in 1994 , respectively ${ }^{(33,34)}$.

In the period from 2000 to 2010, three Demographic and Health Surveys (DHS) were conducted in Armenia at 5 -year intervals. Over these 10 years the prevalence of underweight among children under the age of 5 years rose from $2 \cdot 6 \%$ to $4 \cdot 8 \%$, while rates of stunting and wasting remained relatively stable at $14.6 \%$ and $3.0 \%$, respectively (all rates were based on NCHS/WHO reference population standards) ${ }^{(35-37)}$. Nevertheless, when compared with estimates reported in $1993^{(31)}$, rates of stunting and wasting appear to have doubled in two decades. The DHS completed in $2010^{(37)}$ reported that stunting begins to increase at 6 months of age, reaching a first peak at the age of $12-17$ months with a rate of $16 \cdot 0 \%$ and a second peak at the age of 36-47 months with prevalence of $19.4 \%$. Of the three indicators of undernutrition in Armenia, the high rate of stunting is worrisome as an indicator of a high level of chronic childhood malnutrition. Rates of underweight and wasting also exceed expected prevalences in a well-nourished population $(2 \cdot 3 \%)$, indicating some level of acute malnutrition ${ }^{(31)}$.

Currently, the DHS is the only source of data on child malnutrition in Armenia. However, inconsistencies in the data reported from the different regions of Armenia and across the three reporting periods ${ }^{(35-37)}$ suggest these data may not be reliable. Moreover, DHS is expensive and its continuity may not be warranted. Alternatively, primary paediatric care service coverage is very high in Armenia. Even the most conservative estimate suggests that more than $92 \%$ of infants and toddlers are seen in primary care facilities and have ambulatory (i.e. primary care) charts where their anthropometric data are recorded along with other healthrelated information ${ }^{(37)}$. Therefore, exploring the capacity of the country's primary health-care system in measuring and reporting child growth indicators is worthwhile.

Although risk factors for child undernutrition are generally well known, specific predictors of undernutrition could vary widely from country to country ${ }^{(21)}$. For example, even the countries in the Commonwealth of Independent States (CIS), a group of former Soviet republics of which Armenia is one, demonstrate striking diversity in child nutritional status and rates of malnutrition. This diversity implies the need to identify and address nutritional concerns specific to each former Soviet country ${ }^{(38)}$. The current study aimed to explore the prevalence and main risk factors of undernutrition among children aged 5-17 months residing in Yerevan, the capital of Armenia. Fully one-third of Armenia's population resides in Yerevan, making it a useful setting for study of undernutrition. Infants aged 5-17 months were targeted for study given prior data which suggested bimodal peaks in stunting, with the first peak occurring in this period ${ }^{(35-38)}$.

\section{Methods}

The study used data on anthropometric measurements recorded in children's ambulatory charts to estimate the prevalence of stunting, wasting and underweight among 5-17-month-old children served by Yerevan primary paediatric care facilities. A cross-sectional review of the ambulatory charts of children, selected through a multistage, probability-proportional-to-size cluster sampling technique, was conducted to assure generalizability of findings for Yerevan. In addition to weight and height at the last recommended growth screening, the record review abstracted data on each child's age, gender, weight and length at birth, and contact information. Those children for whom data from the last recommended growth screening were missing were excluded from the study.

This record review was followed by a case-control study aimed to identify predictors of undernutrition among 5-17-month-old children in Yerevan. The cross-sectional record review created a basis for the case-control study. All children with stunting, wasting or underweight identified during the record review were included in this phase of the study as cases. Each case was randomly matched with a control of the same age and gender with normal growth indicators selected from the same record review. Mothers of cases and controls participated in a telephone interview, after providing a verbal consent to participate. The study was conducted according to the guidelines laid down in 
the Declaration of Helsinki. The Institutional Review Board of the American University of Armenia reviewed and approved the study protocol. Data collection took place during April-August 2011.

\section{Variables}

The outcome variables of the study were the presence of stunting, underweight and wasting, or any combination of these three conditions, in a 5-17-month-old child. The study grouped children with any of these outcomes in a single category of 'undernourished' to increase the study power as the numbers of children in each category were small. The study used the WHO Child Growth Standards ${ }^{(29)}$, which were adopted for use in Armenia in 2008 ${ }^{(39)}$. The data on each child's weight and height were plotted in these growth charts. Those children whose height-for-age, weight-for-age or weight-for-height was more than $2 \mathrm{SD}$ below $(<2 \cdot 3$ rd percentile) the median of the reference population were identified as having stunting, underweight or wasting, respectively ${ }^{(31)}$.

Independent variables included parental characteristics (parents' current weight and height, mother's age, education, employment status during and after pregnancy, parity, previous birth interval, any health problems/ chronic diseases during pregnancy, smoking status, knowledge score on child care), child characteristics (length and weight at birth, existence of any inborn health problems, any acute symptoms within $30 \mathrm{~d}$ prior to the last growth screening, feeding patterns including durations of exclusive, predominant and any breastfeeding, consumption of different types of food in the $24 \mathrm{~h}$ prior to the interview, food diversity score, exposure to second-hand smoke) and family socio-economic characteristics (family size, number of employed household members and children under 18 years of age, SES score). The independent variables were either based on single items or constructed on the basis of scores generated from responses to several items. The latter included mother's knowledge score on child care (i.e. sum of correct replies to seven questions on different aspects of child care with a range of 0-7), child's food diversity score (i.e. sum of positive answers to questions regarding consumption of ten different types of food with a range of 0-10) and family's SES score (i.e. based on a cumulative score generated from responses to items on perceived living standards of the family, family's average monthly expenditures and ratio of the total number of household members to the number of employed household members; the responses to each of these items were divided into five ordinal categories from 0 to 4 , and the SES score ranged from 0 to 12 ).

\section{Statistical analyses}

We identified the prevalence of stunting, underweight and wasting in the cross-sectional study sample and investigated the distribution of study variables among cases and controls through descriptive analysis. The characteristics of matched cases and controls were compared through paired $t$ tests and Wilcoxon tests for two related samples. Only two-sided significance levels were considered. This was followed with bivariate and multivariate conditional logistic regression analyses. All study variables were dichotomous or continuous; except mother's education, for which three levels of dummy variables were created with the highest level used as the referent. Before including into the regression analysis, all continuous variables were checked for linearity on the logistic scale. The variables associated with the outcome at the $P<0.25$ level in the bivariate analysis were entered into multivariate analysis in different combinations to check their controlled/mediated effect on the outcome ${ }^{(40,41)}$. The variables included in the final model were checked for interaction and multicollinearity (using variance inflation factor statistics). The analysis was conducted using SPSS version 18 and STATA version 10 statistical software packages.

\section{Results}

The study team reviewed 570 ambulatory charts of 5-17-month-old children. Of these, $8.6 \%$ lacked data on the child's recent recommended growth screening. The recorded data on child's weight and height at the last growth screening in the remaining 521 charts indicated height-for-age below the $2 \cdot 3 \mathrm{rd}$ percentile in $17 \cdot 9 \%$ of charts, weight-for-age below the $2 \cdot 3 \mathrm{rd}$ percentile in $7 \cdot 3 \%$ of charts, and weight-for-height below the $2 \cdot 3 \mathrm{rd}$ percentile in $3 \cdot 1 \%$ of charts. One-fifth of children ( $n$ 107) in the final sample of 521 were judged undernourished. Seventy-one $(66.4 \%)$ had stunting ( $n 63$ ), wasting ( $n 6$ ) or underweight ( $n$ 2); thirty-two (29.9\%) had a combination of two conditions; and four (3.7\%) had all three conditions.

For the case-control study, the 107 undernourished children were randomly matched with controls of the same age and gender from those children whose ambulatory charts were reviewed. However, eighteen pairs (either cases or controls) could not be contacted for various reasons including incorrect telephone number or address or absence from Armenia. Among those contacted, there were no refusals. Thus, data analysis for the case-control phase of the study was based on eighty-nine cases and eighty-nine controls, which gave the study a power of 0.87 to detect a $10 \%$ difference between the groups based on any independent variable of interest.

The mean age of children included in the case-control study was $10 \cdot 6$ (SD 3.7) months. Gender was represented almost equally (48.3\% male and $51 \cdot 7 \%$ female). Table 1 presents the distribution of selected socio-economic, parental and child characteristics among cases and controls and the differences between them identified through paired analysis. Cases had significantly lower weight and length at birth (both $P<0 \cdot 001$ ), shorter mean duration of 
Table 1 Distribution of selected characteristics among cases and controls: 5-17-month-old children in Yerevan, Armenia, April-August 2011

\begin{tabular}{|c|c|c|c|c|c|c|}
\hline & \multirow[b]{2}{*}{$N$} & \multicolumn{2}{|c|}{ Cases } & \multicolumn{2}{|c|}{ Controls } & \multirow[b]{2}{*}{$P$ value } \\
\hline & & Mean or \% & SD & Mean or \% & SD & \\
\hline \multicolumn{7}{|l|}{ Child characteristics } \\
\hline Birth length $(\mathrm{cm})$ & 83 & $47 \cdot 4$ & $3 \cdot 0$ & $50 \cdot 1$ & 1.9 & $<0.001$ \\
\hline Birth weight $(\mathrm{kg})$ & 83 & $2 \cdot 7$ & 0.5 & $3 \cdot 1$ & 0.4 & $<0.001$ \\
\hline Duration of any breast-feeding (months) $\dagger$ & 40 & $4 \cdot 8$ & $4 \cdot 5$ & $7 \cdot 6$ & $4 \cdot 4$ & 0.006 \\
\hline Duration of exclusive breast-feeding (months) & 89 & $2 \cdot 1$ & $2 \cdot 2$ & $2 \cdot 9$ & $2 \cdot 2$ & 0.004 \\
\hline Duration of predominant breast-feeding (months) & 89 & $3 \cdot 2$ & $2 \cdot 3$ & $4 \cdot 6$ & $2 \cdot 7$ & $<0.001$ \\
\hline Score of food diversity & 88 & $5 \cdot 0$ & $1 \cdot 2$ & $5 \cdot 7$ & $1 \cdot 2$ & $<0.001$ \\
\hline Any fruit in the last-day diet (\%) & 89 & $82 \cdot 0$ & - & $94 \cdot 4$ & - & 0.012 \\
\hline Any meat in the last-day diet (\%) & 89 & $36 \cdot 0$ & _- & $60 \cdot 7$ & - & 0.003 \\
\hline Any cheese in the last day diet (\%) & 89 & $66 \cdot 3$ & - & $86 \cdot 5$ & - & 0.001 \\
\hline Low birth weight $(<2.5 \mathrm{~kg})(\%)$ & 84 & $29 \cdot 5$ & - & $2 \cdot 4$ & - & $<0.001$ \\
\hline Acute diseases within $30 \mathrm{~d}$ prior to anthropometrics (\%) & 89 & $16 \cdot 9$ & - & $15 \cdot 7$ & - & 0.853 \\
\hline \multicolumn{7}{|l|}{ Exposure to smoke (\%) } \\
\hline Several times per week or more & 88 & $45 \cdot 5$ & - & $21 \cdot 6$ & - & $<0.001$ \\
\hline Less than several times per week & & $54 \cdot 5$ & - & $78 \cdot 4$ & - & \\
\hline \multicolumn{7}{|l|}{ Maternal characteristics } \\
\hline Age (years) & 83 & $28 \cdot 1$ & 4.9 & $27 \cdot 4$ & $4 \cdot 5$ & $0 \cdot 321$ \\
\hline Weight (kg) & 78 & $59 \cdot 0$ & $11 \cdot 8$ & $59 \cdot 2$ & $10 \cdot 2$ & 0.932 \\
\hline Height $(\mathrm{cm})$ & 77 & $159 \cdot 8$ & $6 \cdot 1$ & $163 \cdot 4$ & 4.9 & $<0.001$ \\
\hline Child-care knowledge score & 89 & $5 \cdot 3$ & $1 \cdot 1$ & $5 \cdot 6$ & $1 \cdot 1$ & 0.060 \\
\hline \multicolumn{7}{|l|}{ Education (\%) } \\
\hline Incomplete school ( $<10$ years) & 89 & $20 \cdot 2$ & - & $16 \cdot 9$ & - & $0 \cdot 147$ \\
\hline School/upper secondary (10-13 years) & & $25 \cdot 8$ & _- & $16 \cdot 9$ & _- & \\
\hline University or higher & & $53 \cdot 9$ & - & $66 \cdot 3$ & - & \\
\hline \multicolumn{7}{|l|}{ Employment (\%) } \\
\hline Employed & 88 & $35 \cdot 2$ & - & $56 \cdot 8$ & - & 0.002 \\
\hline Unemployed & & $64 \cdot 8$ & - & $43 \cdot 2$ & - & \\
\hline \multicolumn{7}{|l|}{ Parity (\%) } \\
\hline 1 & 89 & $58 \cdot 4$ & - & $61 \cdot 8$ & - & 0.631 \\
\hline$>1$ & & $41 \cdot 6$ & - & $38 \cdot 2$ & - & \\
\hline \multicolumn{7}{|l|}{ Previous birth interval (\%) } \\
\hline$<3$ years & 89 & $19 \cdot 1$ & - & $11 \cdot 2$ & - & $0 \cdot 144$ \\
\hline$\geq 3$ years/primiparous & & $80 \cdot 9$ & _- & $88 \cdot 8$ & _ & \\
\hline Health problems during pregnancy (\%) & 89 & $20 \cdot 2$ & - & $15 \cdot 7$ & - & 0.480 \\
\hline \multicolumn{7}{|l|}{ Paternal/household characteristics } \\
\hline Father's weight $(\mathrm{kg})$ & 75 & $73 \cdot 1$ & $10 \cdot 0$ & $80 \cdot 2$ & $12 \cdot 3$ & $<0.001$ \\
\hline Father's height $(\mathrm{cm})$ & 75 & $171 \cdot 3$ & $5 \cdot 6$ & $175 \cdot 8$ & $5 \cdot 5$ & $<0.001$ \\
\hline Number of employed household members & 89 & $1 \cdot 7$ & 0.9 & $2 \cdot 0$ & $1 \cdot 0$ & 0.015 \\
\hline Family's SES score & 79 & $5 \cdot 2$ & $2 \cdot 0$ & $6 \cdot 7$ & $2 \cdot 0$ & $<0.001$ \\
\hline
\end{tabular}

$N$, number of valid pairs; SES, socio-economic status.

*Paired $t$ test for means and related-samples Wilcoxon test for proportions (two-sided $P$ values).

tThis variable was treated as missing if a child still received any breast-feeding at the time of the study.

exclusive $(P=0 \cdot 004)$, predominant $(P<0.001)$ and any breast-feeding $(P=0 \cdot 006)$, lower score of food diversity $(P<0.001)$ and higher exposure to second-hand smoke $(P<0.001)$ than controls. Despite the reported high exposure especially among cases to second-hand smoke (Table 1), only three mothers of cases and three mothers of controls $(3 \cdot 4 \%)$ reported ever smoking and only two $(1 \cdot 1 \%)$ reported that they smoked during pregnancy. Compared with cases, a significantly higher proportion of controls used meat $(P=0 \cdot 003)$, cheese $(P=0 \cdot 001)$ and fruits $(P=0 \cdot 012)$ within $24 \mathrm{~h}$ prior to the survey. Parents of controls were significantly taller than parents of cases (both $P<0 \cdot 001$ ). Fathers' mean weight was also significantly higher among controls compared with cases $(P<0 \cdot 001)$. Mothers of controls were employed significantly more frequently than were mothers of cases $(P=0 \cdot 002)$. The mean number of employed household members $(P=0.015)$ and the mean SES score of the family $(P<0 \cdot 001)$ were significantly higher among controls. The bivariate conditional logistic regression analysis confirmed findings from the paired analyses, identifying statistically significant associations between undernutrition and all of the characteristics mentioned above.

In multivariate conditional logistic regression analysis we constructed different models to assess the controlled effect of independent variables of interest on the outcome. Both father's and mother's height were significantly associated with child's growth after adjusting for spouse's height and for family's SES score, but they lost significance in the final model. The final fitted model identified four significant predictors of child undernutrition: family's SES score $(P=0 \cdot 030)$, child's birth length $(P=0 \cdot 027)$, duration of predominant breast-feeding $(P=0 \cdot 046)$ and score of food diversity $(P=0 \cdot 039$; Table 2$)$. Father's height, although marginally significant $(P=0 \cdot 099)$, was also included in the final model to achieve its better fit. 
Table 2 Predictors of undernutrition* among 5-17-month-old children in Yerevan, Armenia, April-August 2011

\begin{tabular}{lccc}
\hline Characteristic & OR & $95 \% \mathrm{Cl}$ & $P$ valuet \\
\hline Birth length (cm) & 0.50 & $0.27,0.92$ & 0.027 \\
Family's SES score & 0.55 & $0.32,0.94$ & 0.030 \\
Score of food diversity & 0.37 & $0.15,0.95$ & 0.039 \\
Duration of predominant breast-feeding (months) & 0.60 & $0.36,0.99$ & 0.046 \\
Father's height (cm) & 0.89 & $0.77,1.02$ & 0.099 \\
Model's fit statistics: & \multicolumn{3}{c}{ McFadden's adjusted $R^{2}=0.635$} \\
& \multicolumn{3}{c}{ Craximum likelihood $R^{2}=0.643$} \\
& \multicolumn{3}{c}{ Count $R^{2}=0.896$} \\
& AlC $\times n=33.926$ \\
\hline
\end{tabular}

$\mathrm{SES}$, socio-economic status; $R^{2}$, ratio of regression variance to total variance; AIC $\times n$, Akaike information criterion adjusted for the number of observations in the model.

*Undernutrition: stunted, underweight or wasted defined as having an anthropometric measurement more than 2 sD below the median height-for-age, weight-for-age or weight-for-height of the reference population ${ }^{(29)}$, respectively.

tConditional logistic regression analysis.

After controlling for other risk factors of interest, each additional centimetre in birth length was associated with $50 \%$ reduction of the risk of being undernourished. Each one-point improvement in the family's SES score decreased the child's chance of being undernourished by $45 \%$. Each one-point increase in the food diversity score reduced the chance of the child's undernutrition by $63 \%$. Finally, each one-month increase in the duration of predominant breast-feeding was associated with $40 \%$ decreased risk of having undernutrition.

No interactions between the variables included in the model were identified. Variance inflation factor statistics showed no issues of multicollinearity among variables (variance inflation factor values for the variables included in the final model ranged from $1 \cdot 1$ to $1 \cdot 3)^{(42)}$.

\section{Discussion}

The prevalence of stunting in the present sample of 5-17-month-old children in Yerevan, Armenia was $17 \cdot 9 \%$, underweight prevalence was $7 \cdot 3 \%$ and wasting prevalence was $3 \cdot 1 \%$. Overall, about one-fifth $(20 \cdot 5 \%)$ of the sample was undernourished. Considering the closeto-universal coverage of young children with primary paediatric care services ${ }^{(37)}$ and the applied sampling technique, these rates offer close estimates of the prevalences of stunting, underweight and wasting among children aged 5-17 months residing in Yerevan. These rates were calculated based on the WHO Child Growth Standards ${ }^{(29)}$ and were rather close to the DHS 2010 rates for 6-17-month-old children in Armenia calculated using the same WHO Child Growth Standards: $17 \cdot 3 \%$ stunted, $4 \cdot 6 \%$ underweight and $2 \cdot 6 \%$ wasted $^{(37)}$. This comparison shows that the rate of stunting found among children in Yerevan through the present study is not different from that reported for Armenia, while the rates of underweight and wasting we found are slightly higher than those reported for Armenia. This finding suggests relatively more acute malnutrition among children living in this large urban setting ${ }^{(31)}$, which is consistent with studies showing a pattern of more acute malnutrition in urban areas compared with the pattern of more chronic malnutrition in rural areas ${ }^{(43)}$.

According to the WHO classification, the rate of child undernutrition identified in the current study represents a low prevalence of stunting $(<20 \%)$ and underweight $(<10 \%)^{(31)}$. Nevertheless, when compared with data from earlier studies and reports, our findings imply that child undernutrition in Yerevan has not decreased over two decades. Indeed, in the post-Soviet period, most CIS countries experienced serious economic decline accompanied by increasing poverty, growing inequalities and disruption of formerly generous health and social protection systems, and consequent deterioration of child nutrition ${ }^{(38)}$. In 2005, Armenia ranked sixth among twelve CIS countries in terms of the prevalence of stunting and eighth in terms of the prevalence of wasting among children aged 0-59 months ${ }^{(38)}$.

Evidence indicates a reciprocal relationship between malnutrition and immunocompromise. Undernutrition and infections commonly interact, complicating each condition ${ }^{(4)}$. Importantly, infectious diseases such as respiratory diseases and diarrhoea are the third leading cause of infant mortality in Armenia (after perinatal pathology and inborn abnormalities), causing onequarter of all infant deaths ${ }^{(44)}$. Therefore, timely interventions targeting the risk factors of undernutrition in children have the potential to substantially reduce morbidity and mortality.

According to our findings, predictors of undernutrition among 5-17-month-old children in Yerevan are low birth length of the child, low SES of the family, lack of diversity in the child's diet and shorter duration of predominant breast-feeding. Father's low height was marginally significantly associated with the outcome in the final model. All of these risk factors are well known and are often interconnected. Underlying causes of undernutrition include factors adversely influencing the child's health, adequate feeding and care. Poverty is recognized as the 
most important among these factors ${ }^{(12-14,18,19,45-47)}$. According to a recent meta-analysis of DHS data in selected countries, children from families in the lowest wealth quintile have about twice as much stunting as those from the highest wealth quintile ${ }^{(11)}$. In our study also, poor SES was a strong independent predictor of a child's undernutrition. Poverty restricts parents' ability to ensure adequate care, nutrition and a healthy environment for their children. For example, meat and dairy products supply essential protein and micronutrients but are usually more expensive than vegetable foodstuffs. Low intake of these food items is a risk factor for stunting ${ }^{(4)}$. Existing literature suggests a consistent wide gap between the proportions of children in the highest and lowest wealth quintiles who receive animal-source foods in the $24 \mathrm{~h}$ prior to the survey ${ }^{(11)}$. This observation is consistent with our findings: compared with controls, a significantly lower proportion of cases consumed meat products and cheese, their food diversity score was also much lower and this factor appeared to be the strongest predictor of child undernutrition in the final adjusted model. Since mothers of cases and controls were not different from each other in terms of educational level or child-care knowledge score, and children were not different in terms of frequency of acute disease within $30 \mathrm{~d}$ prior to the growth screening (Table 1), poverty is likely the most probable underlying reason for the poorer diet of cases compared with controls.

Food diversity score in the present study was a measure of adequacy of complementary feeding. In this sense, it was closely related to the next identified predictor of child undernutrition: duration of predominant breast-feeding. The mean duration of predominant breast-feeding for undernourished children was $3 \cdot 2$ months, considerably shorter than for children with normal growth ( 4.6 months) and almost two times shorter than the recommended duration of 6 months. The majority of breast-feeding mothers in Armenia and other CIS countries practise predominant breast-feeding ${ }^{(38)}$, as they still follow the recommendations of Soviet medicine of giving neonates water and small amounts of nonnutritional liquids (e.g. herbal tea) right from birth. Inappropriate breast-feeding together with the limited diversity of complementary food and inadequate consumption of animal-source protein and fruits could lead to a deficiency in the nutrients essential for normal growth $^{(48,49)}$. The onset of worsening growth from 6 months of age ${ }^{(37)}$ also indicates that shorter duration of breast-feeding with inadequate complementary feeding could be the main area of concern. The pattern of rapidly declining growth during 6-35 months of age combined with inadequate breast-feeding and late and/or scarce consumption of a protein- and micronutrient-rich diet is observed in other CIS countries as well and is considered an important underlying factor of child undernutrition in these countries ${ }^{(38)}$.
Child's short length at birth was also an independent predictor of child undernutrition in the present study. This finding is consistent with literature indicating that low birth length is a stronger determinant of stunting in childhood and later in life than low birth weight or BMI, especially among children born small for gestational age ${ }^{(50-52)}$. Short length at birth is considered to be more indicative for the presence of genetic predisposition and/ or spontaneous hormonal disturbances leading to short stature $^{(50,51)}$. This predictor of child undernutrition is closely connected with parent's stature and nutritional status. Maternal malnutrition is a proven predictor of small-for-gestational-age birth $^{(53)}$. In the present study, however, mother's weight was not related to the child's nutritional status while father's height was. This indicates the importance of parents' stature for growth patterns of a child - a finding consistent with the literature ${ }^{(5,28,45,47,54,55)}$. Short length at birth is also related to factors affecting fetal growth patterns, such as gestational illnesses, stress and inadequate support during pregnancy ${ }^{(56,57)}$. Appropriate preconceptional and prenatal care interventions are shown to be effective in addressing these problems and reducing the rates of intra-uterine growth retardation ${ }^{(57)}$.

A child's regular exposure to second-hand smoke was also strongly positively associated with undernutrition in the paired and bivariate analyses, but became insignificant when controlled for other variables. However, this finding deserves attention, as a recent study identified an association between father's smoking and undernutrition among children under 5 years of age, especially those from poorer families ${ }^{(58)}$. In the majority of households in Armenia, fathers and other male family members are the main source of second-hand smoke. Smoking among women is much less prevalent and smoking during pregnancy is very $\operatorname{rare}^{(37,59)}$. The association between paternal smoking and child undernutrition could possibly be explained by recurrent respiratory diseases in children because of regular exposure to smoke, as well as by the negative effect of smoking on the family's budget making diverse food less affordable ${ }^{(58)}$.

Although a recent study found an association between parents' education and childhood undernutrition in Armenia $^{(60)}$, we did not reveal significant relationships between mother's education or child-care knowledge score and child's nutritional status. The reason for this finding could be the following: the current study included only the Yerevan population, which is relatively homogeneous in terms of access to basic education and childcare knowledge.

We relied on child growth measurements recorded in ambulatory charts filled in by primary health-care providers. We did not check the precision of these measurements, but the consistency of our findings with DHS data could be indirect evidence of the accuracy of our data. As the proportions of wasted and underweight children among the cases were small, the study did not 
have enough power to conduct separate analysis of risk factors for each of the three undernutrition indicators.

The response rate for the case-control study was 100\%. For different objective reasons, we could not contact $16 \cdot 8 \%$ of the initially selected case-control pairs. However, according to the data available from ambulatory charts, the characteristics of those left out were not significantly different from the characteristics of those who were included in the study.

The study findings suggest that factors determining the growth patterns of children in Yerevan are mostly behavioural and environmental, and thus modifiable. The following measures have potential to drastically improve the situation with child undernutrition in Yerevan:

1. reduction of poverty with particular emphasis on reducing inequalities in food affordability, distribution and use;

2. promotion of breast-feeding and adequate complementary feeding practices;

3. provision of optimal preconceptional care and interventions during and after pregnancy; and

4. promotion of optimal behaviour and environment during pregnancy and thereafter, including protection from second-hand smoke.

Although the present study was restricted to the children living in Yerevan, Armenia, most of its findings are consistent with reports from the other CIS countries ${ }^{(38)}$. Thus, the study's results and recommendations may have much broader implication.

\section{Acknowledgements}

Sources of funding: This research received no specific grant from any funding agency in the public, commercial or not-for-profit sectors. Conflicts of interest: The authors have no conflict of interest. Authors' contributions: All authors participated in conceptualizing the study and designing the survey instrument. L.H. conducted the study and performed the analysis. A.D. and V.P. contributed substantially to the analysis and interpretation of the data. A.D. wrote the manuscript. V.P. reviewed and critically revised the manuscript. All authors read and approved the final manuscript. Acknowledgements: The authors are grateful to Professor Sarah H. Kagan for her thorough review and feedback on the manuscript.

\section{References}

1. Nandy S, Irving M, Gordon D et al. (2005) Poverty, child undernutrition and morbidity: new evidence from India. Bull World Health Organ 83, 210-216.

2. Dewey KG \& Begum K (2011) Long-term consequences of stunting in early life. Matern Child Nutr 7, Suppl. 3, 5-18.

3. Abubakar A, Holding P, Van de Vijver FJR et al. (2010) Children at risk for developmental delay can be recognized by stunting, being underweight, ill health, little maternal schooling or high gravidity. J Child Psychol Psychiatry 51, 652-659.

4. Scrimshaw NS \& SanGiovanni JP (1997) Synergism of nutrition, infection, and immunity: an overview. Am J Clin Nutr 66, issue 2, 464S-477S.

5. Martorell R \& Zongrone A (2012) Intergenerational influences on child growth and undernutrition. Paediatr Perinat Epidemiol 26, 302-314.

6. Stevens GA, Finucane MM, Paciorek CJ et al. (2012) Trends in mild, moderate, and severe stunting and underweight, and progress towards MDG 1 in 141 developing countries: a systematic analysis of population representative data. Lancet 380, 824-834.

7. de Onis M, Blossner M, Borghi E et al. (2004) Methodology for estimating regional and global trends of child malnutrition. Int J Epidemiol 33, 1260-1270.

8. World Health Organization (2011) Millennium Development Goals (MDGs). Progress towards the health-related MDGs. Fact sheet no. 290. http://www.who.int/mediacentre/ factsheets/fs290/en/index.html (accessed November 2012).

9. Ezzati M, Lopez AD, Rodgers A et al. (2002) Selected major risk factors and global and regional burden of disease. Lancet 360, 1347-1360.

10. Black RE, Morris SS \& Bryce J (2003) Where and why are 10 million children dying every year? Lancet 361, 2226-2234.

11. Black RE, Allen LH, Bhutta ZA et al. (2008) Maternal and child undernutrition: global and regional exposures and health consequences. Lancet 371, 243-260.

12. Amsalu S \& Tigabu Z (2008) Risk factors for severe acute malnutrition in children under the age of five: a casecontrol study. Ethiop J Health Dev 22, 21-25.

13. Nahar B, Ahmed T, Brown KH et al. (2010) Risk factors associated with severe underweight among young children reporting to a diarrhoea treatment facility in Bangladesh. $J$ Health Popul Nutr 28, 476-483.

14. Sapkota VP \& Gurung CK (2009) Prevalence and predictors of underweight, stunting and wasting in under-five children. J Nepal Health Res Counc 7, 120-126.

15. Janevic T, Petrovic O, Bjelic I et al. (2010) Risk factors for childhood malnutrition in Roma settlements in Serbia. BMC Public Health 10, 509.

16. Rayhan I \& Hayat Khan S (2006) Factors causing malnutrition among under five children in Bangladesh. Pakistan $J$ Nutr 5, 558-562.

17. Mehata S (2008) A case control study on risk factors associated with malnutrition in Dolpa district of Nepal. J Food Sci Technol Nepal 4, 34-37.

18. Das S \& Rahman RM (2011) Application of ordinal logistic regression analysis in determining risk factors of child malnutrition in Bangladesh. Nutr J 10, 124.

19. Jeyaseelan L \& Lakshman M (1997) Risk factors for malnutrition in south Indian children. J Biosoc Sci 29, 93-100.

20. Ergin F, Okyay P, Atasoylu G et al. (2007) Nutritional status and risk factors of chronic malnutrition in children under five years of age in Aydin, a western city of Turkey. Turk J Pediatr 49, 283-289.

21. Wagstaff A (2003) Child health on a dollar a day: some tentative cross-country comparisons. Soc Sci Med 57, 1529-1538.

22. Santos DS, Santos DN, Silva Rde C et al. (2011) Maternal common mental disorders and malnutrition in children: a case-control study. Soc Psychiatry Psychiatr Epidemiol 46, 543-548.

23. Owor M, Tumwine JK \& Kikafunda JK (2000) Socioeconomic risk factors for severe protein energy malnutrition among children in Mulago Hospital, Kampala. East Afr Med J 77, 471-475.

24. Prentice A (1994) Extended breast-feeding and growth in rural China. Nutr Rev 52, 144-146. 
25. Kramer MS \& Kakuma R (2004) The optimal duration of exclusive breastfeeding: a systematic review. Adv Exp Med Biol 554, 63-77.

26. Victora CG, Smith PG, Vaughan JP et al. (1989) Infant feeding and deaths due to diarrhea. A case-control study. Am J Epidemiol 129, 1032-1041.

27. WHO Collaborative Study Team on the Role of Breastfeeding on the Prevention of Infant Mortality (2000) Effect of breastfeeding on infant and child mortality due to infectious diseases in less developed countries: a pooled analysis. Lancet 355, 451-455.

28. Dewey KG (1997) Cross-cultural patterns of growth and nutritional status of breast-fed infants. Am J Clin Nutr 67, 10-17.

29. de Onis M, Garza C, Onyango AW et al. (2006) WHO Child Growth Standards. Acta Paediatr 95, Suppl. 450; available at http://www.who.int/childgrowth/standards/ Acta_95_S450.pdf

30. Binagwaho A, Ratnayake N \& Smith Fawzi MC (2008) Holding multilateral organizations accountable: the failure of WHO in regards to childhood malnutrition. Health Hum Rights 10; available at http://hhrjournal.org/blog/perspectives/ holding-multilateral-orgs-accountable-the-failure-of-who

31. World Health Organization (1995) Physical Status: The Use and Interpretation of Anthropometry. Report of a WHO Expert Committee. WHO Technical Report Series no. 854. Geneva: WHO.

32. Ogden CL, Kuczmarski RJ, Flegal KM et al. (2002) Centers for Disease Control and Prevention 2000 growth charts for the United States: improvements to the 1977 National Center for Health Statistics version. Pediatrics 109, 45-60.

33. National Institute of Health (1993) Emergency Public Health Information Surveillance System. Yerevan: National Institute of Health.

34. National Institute of Health (1994) Emergency Public Health Information Surveillance System. Yerevan: National Institute of Health.

35. National Statistical Service, Ministry of Health \& ORC Macro (2001) Armenia Demographic and Health Survey 2000. Calverton, MD: National Statistical Service, Ministry of Health and ORC Macro.

36. National Statistical Service, Ministry of Health \& ORC Macro (2006) Armenia Demographic and Health Survey 2005. Calverton, MD: National Statistical Service, Ministry of Health and ORC Macro.

37. National Statistical Service, Ministry of Health \& ICF International (2012) Armenia Demographic and Health Survey 2010. Calverton, MD: National Statistical Service, Ministry of Health and ICF International.

38. Cattaneo A, Timmer A, Bomestar T et al. (2008) Child nutrition in countries of the Commonwealth of Independent States: time to redirect strategies? Public Health Nutr 11, 1209-1219.

39. Ministry of Health, Republic of Armenia (2008) Order $N$ $860 A, 17.06 .2008$. Yerevan: Ministry of Health.

40. Menard S (2010) Logistic Regression: From Introductory to Advanced Concepts and Applications. London: SAGE Publications.

41. Hosmer DW \& Lemeshow S (2000) Applied Logistic Regression. New York: Wiley-Interscience.

42. Allison PD (2012) Logistic Regression Using SAS: Theory and Application, 2nd ed. Cary, NC: SAS Institute Inc.
43. Haddad L, Ruel MT \& Garrett JL (1999) Are urban poverty and undernutrition growing? Some newly assembled evidence. World Dev 27, 1891-1904.

44. National Statistical Service (2011) Statistical Yearbook of Armenia. Yerevan: National Statistical Service; available at http://www.armstat.am/en/?nid= 45\&year=2011

45. Sharghi A, Kamran A \& Faridan M (2011) Evaluating risk factors for protein-energy malnutrition in children under the age of six years: a case-control study from Iran. Int J Gen Med 4, 607-611.

46. Rahman A, Chaudhury S, Karim A et al. (2008) Factors associated with nutritional status of children in Bangladesh: a multivariate analysis. Demogr India 37, 95-109.

47. Zottarelli LK, Sunil TS \& Rajaram S (2007) Influence of parental and socioeconomic factors on stunting in children under 5 years in Egypt. East Mediterr Health J 13, 1330-1342.

48. Rivera JA, Hotz C, Gonzalez-Cossio T et al. (2003) The effect of micronutrient deficiencies on child growth: a review of results from community-based supplementation trials. J Nutr 133, 11 Suppl. 2, 4010S-4020S.

49. Ruel MT (2003) Operationalizing dietary diversity: a review of measurement issues and research priorities. J Nutr $\mathbf{1 3 3}$, 11 Suppl. 2, 3911S-3926S

50. Luo ZC, Albertsson-Wikland K \& Karlberg J (1998) Length and body mass index at birth and target height influences on patterns of postnatal growth in children born small for gestational age. Pediatrics 102, E72.

51. Albertsson-Wikland K, Boguszewski M \& Karlberg J (1998) Children born small-for-gestational age: postnatal growth and hormonal status. Horm Res 49, Suppl. 2, 7-13.

52. Knops NB, Sneeuw KC, Brand R et al. (2005) Catch-up growth up to ten years of age in children born very preterm or with very low birth weight. BMC Pediatr 5, 26.

53. Imdad A \& Bhutta ZA (2012) Maternal nutrition and birth outcomes: effect of balanced protein-energy supplementation. Paediatr Perinat Epidemiol 26, Suppl. 1, 178-190.

54. Subramanian SV, Ackerson LK, Davey Smith G et al. (2009) Association of maternal height with child mortality, anthropometric failure, and anemia in India. JAMA 301, 1691-1701.

55. Sichieri R, Taddei JA \& Everhart JE (2000) Influence of parental height and sociodemographic factors on adolescent height in Brazil. J Adolesc Health 26, 414-419.

56. Ferraz EM, Gray RH \& Cunha TM (1990) Determinants of preterm delivery and intrauterine growth retardation in north-east Brazil. Int J Epidemiol 19, 101-108.

57. Siegel E (1985) Low birth weight and preterm birth: the emerging importance of prevention. Soz Praventivmed 30, 118-124.

58. Chowdhury F, Chisti MJ, Hossain MI et al. (2011) Association between paternal smoking and nutritional status of under-five children attending Diarrhoeal Hospital, Dhaka, Bangladesh. Acta Paediatr 100, 390-395.

59. Demirchyan A, Petrosyan V \& Thompson ME (2012) Gender differences in predictors of self-rated health in Armenia: a population-based study of an economy in transition. Int J Equity Health 11, 67.

60. Harutyunyan $\mathrm{T}$ (2011) Socio-economic determinants of child nutritional status in Armenia: the analysis of 2000 and 2005 Demographic and Health Surveys. PhD Thesis, University of North Carolina at Charlotte. 